\title{
Improving the efficiency of corporate management of agricultural enterprises
}

\author{
Sergey Yekimov 1,*, Vladimir Purtov ${ }^{2}$, Ievgen Buriak ${ }^{3}$, Dmytro Kabachenko ${ }^{4}$, and \\ Anastasiia Poltorak ${ }^{5}$ \\ ${ }^{1}$ Publishing House "Education and Science”, Olstynska 607/1, Praha 8, 18100, Czech Republic \\ ${ }^{2}$ V.N. Karazin Kharkiv National University, Svobody Square, 4, Kharkiv, Ukraine \\ ${ }^{3}$ Kremenchuk Mykhailo Ostrohradskyi National University, Kremenchuk, Ukraine \\ ${ }^{4}$ Dnipro University of Technology, Dnipro, Ukraine \\ ${ }^{5}$ Mykolayiv National Agrarian University, Mykolayiv,Ukraine
}

\begin{abstract}
Financial indicators play an important role in the management of an agricultural enterprise. the tasks of the management of the agricultural enterprise are to control the efficiency of employees and maintain the financial stability of the enterprise. In this paper, the problem of ensuring effective management of an agricultural enterprise was investigated. The activity of an agricultural enterprise depends on the influence of external factors: political and legal, technical and economic, ecological and economic, demographic, socio-cultural. We studied the question of how to take into account the influence of variable external factors in the management of an agricultural enterprise. Traditional methods based on financial analysis data, in our opinion, do not fully reflect the situation in the agricultural enterprise. International management accounting standards are optional, but they allow for the use of more flexible indicators in management accounting that take into account the activities of a particular agricultural enterprise. This will facilitate short and medium-term planning at the agricultural enterprise and facilitate the achievement of the enterprise's tactical and strategic goals.
\end{abstract}

\section{Introduction}

Due to the high cost of debt capital for countries with economies in transition, including the CIS countries, the possibility of borrowing through the issuance of securities is very limited. as a rule, this is due to corruption, shortcomings in legislation, structural deformation of the economy, imperfection of the judicial system, and flaws in corporate governance. Therefore, the search for methods to improve the efficiency of corporate governance can have a positive effect without increasing the cost of capital of the enterprise and without increasing the level of its capitalization.

According to [1] corporate governance is a system of enterprise management provided for by law in order to improve the efficiency of its functioning, taking into account the interests of its owners and other counterparties.

\footnotetext{
*Corresponding author: 3701313@mail.ru
} 
According to [2] corporate governance should combine the practice of economic activity and legislative norms, which in turn allows you to profitably attract human and material resources.

According to [3],[4] the functions of corporate regulation can be divided into general and special. The general ones are aimed at managing the company as a whole (managing the company's assets, managing the planning of the company's activities). Special functions of corporate regulation are related to the management of marketing, finance, production, and personnel.

According to [5] corporate governance should be based on the following basic principles:

1) compliance with the objectives and goals of the enterprise;

2) consistency and consistency in their activities;

3) innovative development;

4) balance and completeness in the choice of means of influence;

5) compliance with public values;

6) motivation of staff activities;

According to [6],[7] in transition economies, corporate governance typically faces the following challenges:

1) Real corporate governance is complex in nature, and there is a problem of lack of qualified personnel for its implementation;

2) Errors and shortcomings in its implementation can be interpreted as the inability to apply corporate governance in a particular enterprise;

3) The external environment of the functioning of a business entity is associated with the presence of many uncertain factors. For example, the imperfection of the legal framework, corruption, which limit the capabilities of the enterprise and prevent its effective operation.

4) Lack of effective control over the activities of business entities by the state;

5) Owners of controlling stakes often ignore the interests of small shareholders, primarily in matters of reorganization of the company and payment of dividends.

In our opinion, the main goal of corporate governance should be to improve the efficiency of the company's functioning, taking into account the interests of investors, creditors, employees and management of the enterprise and society as a whole.

According to [8] compliance with the requirements of international standards helps to protect the interests of investors, society, and corporations, reduces corruption risks, and limits abuses by the authorities and management of the enterprise

The development of countries with economies in transition is largely dependent on the activities of their corporate structures.

In [9] criteria for evaluating the effectiveness of corporate activities are proposed (figure 1): 


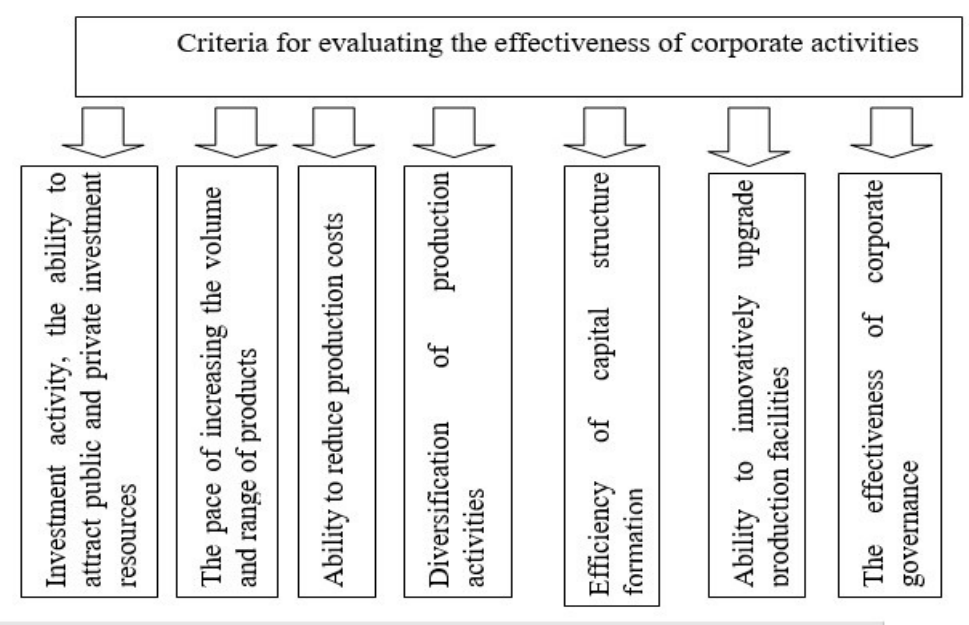

Fig. 1. Criteria for evaluating the effectiveness of corporate activities.

According to [10] management of a corporate enterprise is a system of relationships designed to regulate the procedures and rules for decision-making, as well as the delegation of rights and obligations between individual divisions of the enterprise.

Its effectiveness is achieved by increasing profitability and competitiveness, as well as by establishing principles of effective management and control over its activities.

According to [11],[12] the basic criteria for effective management are indicators that characterize the results of economic activity of the enterprise and the implementation of the principles of corporate governance.

Countries with economies in transition tend to produce products with low added value, and a significant share of GDP in most of them belongs to the agricultural sector of the economy. Although in agriculture there are enterprises of various forms of ownership: personal farms, farms, limited liability companies, agricultural holdings. But it is argohodlings, as a rule, that produce most of the products.

\section{Materials and methods}

In writing this paper, the authors used an analytical method, with the help of which the studied problems were considered in their unity and development. Taking into account the goals and objectives of the study, the structural and functional method of scientific research was used. This made it possible to study some of the problems associated with improving the efficiency of corporate management of an agricultural enterprise.

\section{Results}

For strategic planning of the development of economic entities, it is necessary to have longterm guidelines and adapt to the conditions in which they operate.

According to [7] the following components of the external environment of the enterprise can be distinguished: technical and economic, political and legal, foreign economic, demographic, environmental and climatic, and socio-cultural.

In our opinion, if the external environment is stable or its evolution can be predicted, then there is a possibility of effective medium - and long-term planning in the enterprise.

Analyzing the impact of the external environment on the agricultural sector of the Ukrainian economy, it can be noted that the basis of export-oriented agricultural sectors is 
the cultivation of sunflower and grain crops. The factors affecting the effectiveness of corporate governance are shown in Figure 2.

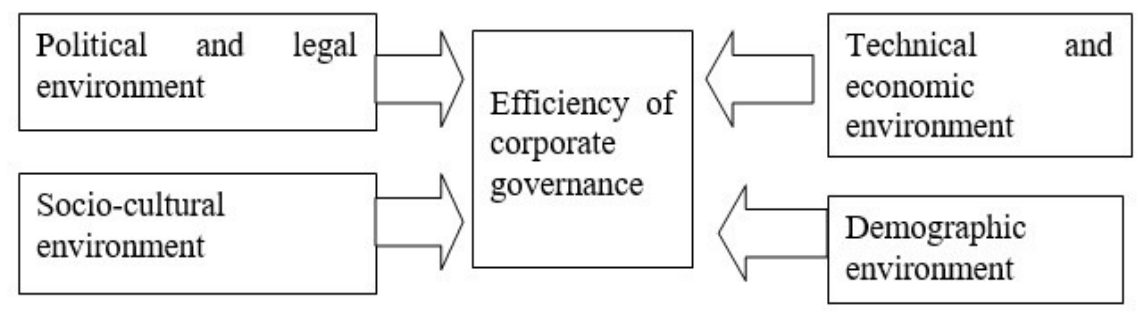

Fig. 2. Factors affecting the effectiveness of corporate governance.

The technical and economic component of the external environment is underdeveloped, its innovative development is at a very low level. The socio-cultural component of the external environment is characterized by poor development of rural areas and low living standards of local residents. The political and legal component is characterized by insufficiently effective state financial policy and corruption risks. The demographic component of the external environment is characterized by insufficient mechanization of production, as well as low qualification of the labor force.

The effectiveness of corporate governance largely depends on how effectively the financial resources of the enterprise are used. Managing the asset structure of an enterprise should harmoniously combine borrowed and own sources of financing, which in turn helps to reduce financial risks and strengthen financial stability.

The financial results of the corporation's business activities are highly dependent on external factors. In our opinion, along with international accounting and reporting standards, it is also necessary to develop and implement additional indicators that characterize the company's activities taking into account local specifics. This, in our opinion, will simplify the corporation's achievement of strategic and tactical goals and facilitate short - and medium-term planning of its activities.

When managing financial flows in corporations, great attention should be paid to ensuring the financial balance of the enterprise and ensuring the required liquidity of its assets.

In our opinion, among the performance indicators of the corporation should be those that link the results of the work of individual divisions and responsibility centers of the enterprise with the financial results of the company as a whole.

\section{Discussion}

In our opinion, the development strategy of the economic society should be adapted to the changing conditions of the external environment and at the same time combine this with the need to obtain maximum profit from economic activities.

In our opinion, the implementation of structural changes in the company, maintaining stable growth, strengthening the company's position in the agricultural market, and investment activities should be used as components of the corporation's development strategy.

Taking into account the external and internal environment of agricultural enterprises along with an increase in production volumes and increased profits for successful functioning of the Corporation requires upgrading fixed assets, improving the quality of products in accordance with international standards, improving the quality of life of employees, increase in sales of agricultural products and high added value. 


\section{Conclusions}

The role of financial results in the effective management of an agricultural enterprise is quite high. The task of the head of an agricultural enterprise is not only to control the effective work of employees, but also to make decisions aimed at improving the financial stability of the organization.

Any organization exists at the expense of making a profit. And the amount of this profit should be such that not only meet the main obligations, that is, be solvent, but also have a reserve of funds that will be used for the development of the organization.

The agricultural sector has a large amount of costs, for land, keeping pets, caring for plantings, servicing specialized equipment. But at the same time, this sector depends on external factors, for example, weather. Accordingly, adverse weather conditions can reduce the value of the crop, and this in turn will affect the financial results.

A competent manager of an agricultural enterprise, before making a management decision, should conduct a comprehensive analysis of the external and internal environment, identify all possible threats and plan methods of combating them. At all stages of the solution implementation, control is necessary, and when errors are detected, they are immediately eliminated.

Well-thought-out management decisions lead to an increase in the financial stability and profitability of the enterprise. Due to these criteria, the organization develops and strengthens its competitive position in the market, which increases the chances of winning the competition in market conditions. A solvent profitable enterprise is attractive from the point of view of the object of investment, which is very important for an agricultural enterprise. Due to investments, the agricultural enterprise has the opportunity to purchase new high-tech devices used in agricultural production, which will contribute to improving labor productivity and product quality.

\section{References}

1. K. Prib, Practice of crisis management in agricultural enterprises, Ekonomika APK, 51 (2019)

2. K. Kovács, Agricultural Enterprises in Hungary (2018)

3. D.M. Akbasheva, R.A. Goguev, A.R. Salpagarova, A. Arova, L. Urusova, Accounting at an agricultural enterprise, Scientific development trends and education (2020)

4. I. Kravchuk, S. Logvinenko, Financial Management of Agricultural Enterprises. Business Inform, 3, 136 (2019)

5. O. Sarapina, T. Pinchuk, T. Shram, Scientific Notes of Taurida National V.I. Vernadsky University. Series: Economy and Management, 70(3), 62 (2020)

6. N. Pylypiv, I. Ambroziak, Agricultural enterprise management system (2016)

7. V. Voskolupov, Bioeconomics and Agrarian Business 11, 5 (2020)

8. M. Rudenko, Ekonomika ta upravlìnnâ APK, 76 (2019)

9. M. Zos-Kior, V. Ilin, M. Kryvobik, Pryazovskyi Economic Herald (2020)

10. V. Tkach, E. Medyukha, N. Zemlyakova, L. Pudeyan, K. Chanturia, E. Moskvitin, IOP Conference Series: Earth and Environmental Science 403, 012134 (2019)

11. N. Nosan, Modern Economics, 22, 72 (2020)

12. A. Chykurkova, M. Gorichovski, Management system for agricultural enterprises competitiveness, The economic discourse, 70 (2019)

13. P. Bryla, Erratum to: Managing Agricultural Enterprises (2018) 